\title{
PREVALENCE OF METABOLIC SYNDROME AMONG DELTA UNIVERSITY FOR SCIENCE AND TECHNOLOGY (DUST) STUDENTS
}

\section{Diabetology}

Elsayed A. Eid*

MD Internal Medicine and Endocrinology Department, Delta University for Sciences and Technology, Gamasa, Egypt *Corresponding Author

Abdelaziz M. Medical Physiology Department, Mansoura Faculty of Medicine and Mansoura, Egypt
Hussein

Abdelnasar
Badawy

Medical Biochemistry Department, Mansoura Faculty of Medicine and Mansoura, Egypt

\section{ABSTRACT}

Background: Metabolic syndrome (MetS) is clinical condition associated with multiple complications. Corresponding with the increased obesity epidemic in young people, increased rates of MetS among this population was reported.

Aim of work: to document the prevalence of MetS among Delta University for Science and Technology (DUST) students.

Methods: 300 students were examined for prevalence of MetS. For the diagnosis of MetS, we adopted the Harmonized Joint Scientific Statement (HJSS) on metabolic syndrome recommendations.

Results: The present study included 300 students. They comprised 118 male (39.3\%) and 182 female (60.7\%) with an age of $19.1 \pm 0.8$ years. MetS was diagnosed in only 3 students $(1.0 \%)$. Individual MS criteria included central obesity $(48.0 \%)$, increased serum triglycerides ( $3.7 \%$ ), reduced HDL (11.3\%), hypertension ( $5.0 \%$ ) and hyperglycemia $(0.3 \%)$. Only 1 criterion of MetS diagnosis was reported in $48.0 \%$ of students while 2 criteria were reported in $8.7 \%$ of students and 3 criteria were reported in $1 \%$ of students. Comparison between males and females revealed significantly higher frequency of central obesity in females $(33.1 \%$ versus $57.7 \%, \mathrm{p}<0.001)$. In comparison, males had significantly higher frequency of increased serum triglycerides $(7.6 \%$ versus $1.1 \%, \mathrm{p}=0.003)$.

Conclusions: The prevalence of MetS is $1.0 \%$. Central obesity was the most common criterion. Females had significantly higher rate of central obesity and MetS criteria.

\section{KEYWORDS}

Metabolic syndrome, central obesity, university students.

\section{INTRODUCTION}

Metabolic syndrome (MetS) is a clinical condition that clusters abdominal obesity, dyslipidemia, hyperglycemia and hypertension. The average prevalence of MetS in the adult populations is about 31.0 $\%$. The syndrome is linked to increased odds of cardiovascular disease and all-cause mortality (Engin, 2017).

Recent reports recognized alarmingly increased prevalence of MetS among younger people (Fu and Prasad, 2015). The increased prevalence of MetS in the younger populations is related to the changed life style favoring lower physical activity and certain dietary preferences (Machado-Rodrigues et al., 2015).

Even in the younger age, MetS is associated with many morbidities including altered liver functions (Dimitrijevic-Sreckovic et al., 2013), non-alcoholic fatty liver disease (Silveira et al., 2013), diabetes mellitus (Weinstock et al., 2015), obstructive sleep apnea (Ou et al., 2015), dyslipidemia (Bermúdez-Cardona and Velásquez-Rodríguez, 2016) and impaired bone health (da Silva et al., 2017).

Early identification of MetS in youngsters is of paramount significance. It's crucial to determine the related risk factors and clinical patterns to help appropriate planning for management and prevention (Agirbasli et al., 2016). There are limited published data on the prevalence of MetS among young adult in Egypt (Mahrous et al., 2018). So, the aim of the current study was to assess the prevalence of MetS among DUST students and identify potential risk factors that can be used for the prevention and management of MetS in young adults.

\section{SUBJECTS AND METHODS \\ Subjects}

The present study is a cross-sectional study. It was conducted at Delta University for Science and Technology (DUST), Gamasa, Egypt. The study protocol was approved by the local ethical committee in accordance with the Helsinki Declaration on clinical research involving human subjects. All participants gave informed consent before being included in the study. Three hundred students attending the hospital for routine check-ups were recruited. The eligible participants were selected from two faculties of the university using multistage random sample. The list of all names of faculties was obtained from DUST administration Office. The selected faculties were Faculty of Dentistry and oral medicine, Faculty of Physical Therapy.

\section{Exclusion criteria}

Exclusion criteria were patients with known cardiovascular disease or metabolic or genetic conditions associated with body weight changes. All students were subjected to careful history taking, thorough clinical examination. All subjects were weighed shoeless with light clothes using a standard scale. Hight was assessed using a standard stadiometer. Waist circumference was measured using a tape measure at the top of the iliac crest at the end of exhalation. Systolic and diastolic blood pressures were measured by means of mercurial sphygmomanometers.

\section{Investigations}

- five $\mathrm{ml}$ venous blood sample was collected from each participant by expert nurse after $12 \mathrm{~h}$ of fasting into a sterile tube with clot activator for the measurement of serum lipids and glucose. Blood samples were immediately placed in an icebox for a period not exceeding $3 \mathrm{~h}$. Blood samples were centrifuged and analyzed immediately after separation for blood glucose. Analyses for fasting blood lipids, including triglycerides (TG), HDL-C, and total cholesterol, and fasting blood glucose were carried out by enzymatic colorimetric test, using spectrophotometer (Jenway, Keison International Ltd., Chelmsford, UK).

\section{Assessment of MetS}

For the diagnosis of MetS, we adopted the Harmonized Joint Scientific Statement (HJSS) on metabolic syndrome recommendations. MetS criteria included increased blood pressure $>130 / 85 \mathrm{mmHg}$, elevated FBS $>100 \mathrm{mg} / \mathrm{dL}$, obesity: waist circumference: $>94 \mathrm{~cm}$ (male) $>80$ $\mathrm{cm}$ (female) or body mass index $>30 \mathrm{~kg} / \mathrm{m}^{2}$, dyslipidemia: triglycerides $\geq 150 \mathrm{mg} / \mathrm{dL}$ and high-density lipoprotein cholesterol (HDL-C $\leq 40 \mathrm{mg} / \mathrm{dL}$ (male), $50 \mathrm{mg} / \mathrm{dL}$ (female). MetS was diagnosed in the presence of any three criteria (Alberti et al., 2009).

\section{Statistical analysis}

Data were represented as mean $\pm \mathrm{SD}$ or number and percent. Statistical analysis was computed using SPSS 25 (IBM, USA). Comparisons were achieved using Fisher exact test or chi-square test as appropriate. Pvalue less than 0.05 was considered statistically significant. 
RESULTS

The present study included 300 students. They comprised 118 males $(39.3 \%)$ and 182 females $(60.7 \%)$ with an age of $19.1 \pm 0.8$ years. MetS was diagnosed in only 3 students $(1.0 \%)$. Individual MS criteria included central obesity $(48.0 \%)$, increased serum triglycerides $(3.7$ $\%)$, reduced HDL (11.3\%), hypertension (5.0\%) and hyperglycemia $(0.3 \%)$. Only 1 criterion of MetS diagnosis was reported in $48.0 \%$ of students while 2 criteria were reported in $8.7 \%$ of students and 3 criteria were reported in $1 \%$ of students (Table 1 ).

Table-1 Prevalence of metabolic syndrome and its components in the studied subjects

\begin{tabular}{|l|c|}
\hline Metabolic syndrome n (\%) & $3(1.0)$ \\
\hline Metabolic syndrome criteria n $(\%)$ & $144(48.0)$ \\
\hline Central obesity & $11(3.7)$ \\
\hline Increased serum triglycerides & $34(11.3)$ \\
\hline Reduced HDL & $15(5.0)$ \\
\hline Hypertension & $1(0.3)$ \\
\hline Hyperglycemia & $144(48.0)$ \\
\hline Number of metabolic syndrome criteria \\
\hline 1 criterion & $26(8.7)$ \\
\hline 2 criteria & $3(1.0)$ \\
\hline 3 criteria & \\
\hline
\end{tabular}

HDL: high density lipoprotein.

Comparison between males and females revealed significantly higher frequency of central obesity in females $(33.1 \%$ versus $57.7 \%$, p $<$ $0.001)$. In comparison, males had significantly higher frequency of increased serumtriglycerides $(7.6 \%$ versus $1.1 \%, \mathrm{p}=0.003)$ (Table- 2$)$.

Table-2 Comparison between males and females regarding metabolic syndrome criteria $(n=300)$

\begin{tabular}{|l|c|c|c|}
\hline & $\begin{array}{c}\text { Males } \\
\mathbf{n = 1 1 8}\end{array}$ & $\begin{array}{c}\text { Females } \\
\mathbf{n = 1 8 2}\end{array}$ & P value \\
\hline Metabolic syndrome n (\%) & $1(0.9)$ & $2(1.1)$ & 0.83 \\
\hline Metabolic syndrome individual criteria $\mathrm{n}(\%)$ \\
\hline Central obesity & $39(33.1)$ & $105(57.7)$ & $<0.001$ \\
\hline Increased serum triglycerides & $9(7.6)$ & $2(1.1)$ & 0.003 \\
\hline Reduced HDL & $12(10.2)$ & $22(12.1)$ & 0.61 \\
\hline Hypertension & $4(3.4)$ & $11(6.0)$ & 0.3 \\
\hline Hyperglycemia & $1(0.9)$ & - & 0.21 \\
\hline Number of metabolic syndrome criteria n (\%) \\
\hline 1 criterion & $44(37.3)$ & $63(34.6)$ & 0.01 \\
\hline 2 criteria & $9(7.6)$ & $100(55.0)$ & \\
\hline 3 criteria & $1(0.9)$ & $2(1.1)$ & \\
\hline
\end{tabular}

HDL: high density lipoprotein

Comparison between students with central obesity and students without revealed higher - albeit insignificant - frequency of MetS in students with central obesity (Table-3)

Table-3 Comparison between students with central obesity and students without regarding metabolic syndrome criteria

\begin{tabular}{|c|c|c|c|}
\hline & $\begin{array}{c}\text { Central } \\
\text { obesity } \\
n=144\end{array}$ & $\begin{array}{c}\text { No central } \\
\text { obesity } n=156\end{array}$ & P value \\
\hline Metabolic syndrome n (\%) & $3(2.1)$ & - & 0.07 \\
\hline \multicolumn{4}{|c|}{ Metabolic syndrome individual criteria n (\%) } \\
\hline Increased serum triglycerides & $7(4.9)$ & $4(2.6)$ & 0.29 \\
\hline Reduced HDL & $16(11.1)$ & $18(11.5)$ & 0.91 \\
\hline Hypertension & $7(4.9)$ & $8(5.1)$ & 0.92 \\
\hline Hyperglycemia & - & $1(0.6)$ & 0.34 \\
\hline \multicolumn{4}{|c|}{ Number of metabolic syndrome criteria n (\%) } \\
\hline 1 criterion & $117(81.3)$ & $27(17.3)$ & \multirow[t]{3}{*}{$<0.001$} \\
\hline 2 criteria & $24(16.7)$ & $2(1.3)$ & \\
\hline 3 criteria & $3(2.1)$ & - & \\
\hline
\end{tabular}

HDL: high density lipoprotein.

\section{DISCUSSION}

In the present study, the prevalence of MetS was $1.0 \%$. This figure is close to that reported by the study of Yahia et al., (2017) where MetS wasn't prevalent among 462 students, aged 18-25 years using the National Cholesterol Education Program's Adult Treatment Panel III guidelines. In comparison, the prevalence of MetS was $3.7 \%$ among 402 university students in the study of González Deschamps et al., (2007), $4.6 \%$ among 8226 freshmen students in the study of Yen et al., (2008), 8.1 \% among 1,096 freshmen students in the study of Lin et al., (2009) and $7.6 \%$ in the study of Ruano Nieto et al., (2015). Astonishingly, the prevalence of MetS among university studies using Joint Interim Statement (JIS) criteria was 20.5\% (Barbosa et al., 2016).

Mahrous et al., (2018) found that the overall MetS prevalence among Menoufia University students was $16.7 \%$ which was in line with Al-Isa et al. (2010), who estimated the prevalence of MetS in 431 Kuwaiti adolescents aged 10-19 years and found that the prevalence of MetS was $14.8 \%$ using IDF criteria. Moreover, this was in concordance with Mattsson et al. (2007) who collected their data from 2182 healthy young adults in Finland, and the prevalence of MetS was $13.0 \%$ using the NCEP criteria and $14.9 \%$ using the IDF criteria. The rates found in the present study were higher than those of Al Dhaheri et al.[2016] who revealed a MetS prevalence of $6.8 \%$ among 555 Emirati female college students aged 17-25 years. In addition, Sabir et al (2016) found that the prevalence of MetS among 1012 Sudanese university studen aged $16-25$ years was $8.4 \%$ using IDF criteria and $7.5 \%$ using NCEP ATP-III criteria.

Noteworthy, the variable results of different studies don't necessarily reflect true differences. Feliciano-Alfonso et al., (2010) study showed that prevalence of the MS varied markedly according to the definition employed: 9.2\% using REGODCI (Research Group on Diabetes and Chronic Illnesses) criteria, 2\% using IDF (International Diabetes Federation) criteria, and 2.4\% using AHA (American Heart Association) criteria. In the current study, $48.0 \%$ of the studied subjects had at least one MetS criterion while 2 criteria were identified in $8.7 \%$ of the included students. In the study of Fernandes and Lofgren (2011) on 189 college students, prevalence of 1 or 2 MetS criteria was $28.0 \%$ and $7.4 \%$, respectively where MetS was diagnosed in $3.7 \%$ of subjects. In another study, MetS was diagnosed in $6.8 \%$ of 207 college students aged 18 to 24 years according to the National Cholesterol Education Program Adult Treatment Panel III guidelines. The authors also found that $42.5 \%$ and $13.0 \%$ of students had 1 and 2 MetS components, respectively (Dalleck and Kjelland, 2012). In a third study where MetS was diagnosed in $1.7 \%$ of 702 Brazilian college students, $30.4 \%$ of students manifested at least one and $12.4 \%$ at least two individual components (de Freitas et al., 2013).

In our study, central obesity is the most commonly reported MetS criterion. In contrast, the most frequent criterion in the studies of González, Deschamps et al., (2007) and Yahia et al., (2017) was low HDL-cholesterol (28.9\% and $22.0 \%$ respectively). A cross-sectional study was conducted during the academic year 2016/2017 at Menoufia University on 455 university students aged 18-25 years demonstrated that the overall prevalence of MetS was more frequent among female students. The most prevalent MetS components were increased waist circumference $(41.8 \%)$ followed by high triglyceride levels $(40.2 \%)$ and reduced high-density lipoprotein-cholesterol levels $(36.3 \%)$. The predisposing factors for having MetS included the following: being female, older than 20 years, obese, physically inactive, high levels of stress, and a positive family history of hypertension and diabetes (Mahrous et al., 2018)

Comparison between males and females revealed significantly higher rate of central obesity in females as compared to males. This finding accords with results reported by the study of Ruano Nieto et al., (2015) where increased waist circumferences was more frequently reported in females $(33.67 \%$ vs. 9.55\%). Moreover, in our study, females had significantly higher rate of subjects with 2 MetS criteria in contradiction with the conclusions of Morrell et al., (2012) where males with two MetS criteria was significantly more frequent than females.

In conclusion, the prevalence of MetS in the present study is low However, almost half of the studied student have at least on MetS criterion. In our series, central obesity particularly in females is the core component of MetS criteria. Considering the young age range of the study participants (18-20 years), follow up of those students is recommended.

\section{Conflict of interest}

Authors declared that there is no conflict of interest 


\section{REFERENCES}

. Agirbasli M, Tanrikulu AM, Berenson GS. Metabolic Syndrome: Bridging the Gap from Childhood to Adulthood. Cardiovasc Ther. 2016 Feb;34(1):30-6.

2. Alberti KG, Eckel RH, Grundy SM, Zimmet PZ, Cleeman JI, Donato KA, Fruchart JC, James WP, Loria CM, Smith SC Jr; International Diabetes Federation Task Force on Epidemiology and Prevention; Hational Heart, Lung, and Blood Institute; American Heart Association; World Heart Federation; International Atherosclerosis Society; International Association for the Study of Obesity. Harmonizing the metabolic syndrome: a joint interim state te ; Nation on Epideniology and Prevention, National Heart, Lung, and Blood Institute; American Heart Association; World Heart Federation; International Atherosclerosis Society; and International Association for the Study of Obesity. Circulation. 2009 Oct $20 ; 120(16): 1640-5$

3. Al Dhaheri AS, Mohamad MN, Jarrar AH, Ohuma EO, Ismail LC, Al Meqbaali FT, et al. A cross-sectional study of the prevalence of metabolic syndrome among young female emirati adults. PLoS One 2016;11:7.

4. Al-Isa A, Akanji AO, Thalib L. Prevalence of the metabolic syndrome among female Kuwaiti adolescents using two different criteria. Br J Nutr 2010; 103:77-81.

5. Barbosa JB, dos Santos AM, Barbosa MM, Barbosa MM, de Carvalho CA, Fonseca PC, Fonseca JM, Barbosa Mdo C, Bogea EG, da Silva AA. Metabolic syndrome, insulin resistance and other cardiovascular risk factors in university students. Cien Saude Colet. 2016 Apr;21(4):1123-36.

6. Bermúdez-Cardona J, Velásquez-Rodríguez C. Profile of Free Fatty Acids and Fractions of Phospholipids, Cholesterol Esters and Triglycerides in Serum of Obese Youth with and without Metabolic Syndrome. Nutrients. 2016 Feb 15;8(2):54

7. da Silva VN, Fiorelli LN, da Silva CC, Kurokawa CS, Goldberg TB. Do metabolic syndrome and its components have an impact on bone mineral density in adolescents? Nutr Metab (Lond). 2017 Jan 4;14:1.

8. Dalleck LC, Kjelland EM. The prevalence of metabolic syndrome and metabolic syndrome risk factors in college-aged students. Am J Health Promot. 2012 SepSyndrome risk fact: $27(1): 37-42$.

9. de Freitas RW Jr, de Araújo MF, Marinho NB, de Vasconcelos HC, Lima AC, Pereira DC, Almeida PC, Zanetti ML, Damasceno MM. Prevalence of the metabolic syndrome and its individual components in Brazilian college students. J Clin Nurs. 2013 May;22(9-10):1291-8.

10. Dimitrijevic-Sreckovic V, Soldatovic I, Culafic D, Sreckovic B, Popovic S, Djordjevic P, Ille T. Liver function test changes in centrally obese youth with metabolic syndrome in a Serbian population. Metab Syndr Relat Disord. 2013 Dec;11(6):427-33.

11. Engin A. The Definition and Prevalence of Obesity and Metabolic Syndrome. Adv Exp Med Biol. 2017;960:1-17.

12. Feliciano-Alfonso JE, Mendivil CO, Ariza ID, Pérez CE. Cardiovascular risk factors and metabolic syndrome in a population of young students from the National University of Colombia. Rev Assoc Med Bras (1992). 2010 May-Jun;56(3):293-8.

13. Fernandes J, Lofgren IE. Prevalence of metabolic syndrome and individual criteria in college students. JAm Coll Health. 2011;59(4):313-21.

14. Fu J, Prasad HC. Changing epidemiology of metabolic syndrome and type 2 diabetes in Chinese youth. Curr Diab Rep. 2014 Jan;14(1):447.

15. González Deschamps E, Palmeros Exsome C, Villanueva Sánchez J, Torres Flores B, Bastida S, Vaquero MP, Sánchez-Muniz FJ. [Metabolic syndrome prevalence and its association with the body mass index in university students]. Med Clin (Barc). 2007 Dec 1:129(20):766-9.

16. Lin KP. The relationship between serum uric acid concentration and metabolic syndrome in university freshmen. J Nurs Res. 2009 Dec;17(4):286-92.

17. Mahrous OA, Anwar El Shazly HM, Badr SA, Ibraheem RA, Kasemy ZA, El Sheikh GM. Epidemiology of metabolic syndrome in Menoufia University students. Menoufia Med J 2018;31:839-45

18. Machado-Rodrigues AM, Leite N, Coelho e Silva MJ, Valente-dos-Santos J, Martins RA, Mascarenhas LP, Boguszewski MC, Padez C, Malina RM. Relationship between metabolic syndrome and moderate-to-vigorous physical activity in youth. J Phys Act Health. 2015 Jan; 12(1):13-9.

19. Mattsson N, Ronnemaa T, Juonala M, Viikari J, Raitakari OT. The prevalence of the metabolic syndrome in young adults. The Cardiovascular Risk in Young Finns Study. Intern Med J 2007; 261:159-169

20. Morrell JS, Lofgren IE, Burke JD, Reilly RA. Metabolic syndrome, obesity, and related risk factors among college men and women. J Am Coll Health. 2012;60(1):82-9.

21. Qu XX, Esangbedo IC, Zhang XJ, Liu SJ, Li LX, Gao S, Li M. Obstructive Sleep Apnea Syndrome is Associated with Metabolic Syndrome among Adolescents and Youth in Beijing: data from Beijing Child and Adolescent Metabolic Syndrome Study. Chin Med J(Engl). 2015 Sep 5;128(17):2278-83.

22. Ruano Nieto CI, Melo Pérez JD, Mogrovejo Freire L, De Paula Morales KR, Espinoza Romero CV. [Prevalence of metabolic syndrome and associated risk factors in ecuadorian university students]. Nutr Hosp. 2015 Apr 1;31(4):1574-81.

23. Sabir FM, Hassan DA, Elamin MI. Prevalence of metabolic syndrome among Young Sabir FM, Hassan DA, Elamin MI. Prevalence of metabolic syndrome among Young
Sudanese University students using three different criteria of WHO, IDF and NCEPATPIII. Pediatr Neonatal Nurs 2016;2:2

24. Silveira LS, Monteiro PA, Antunes Bde M, Seraphim PM, Fernandes RA, Christofaro DG, Freitas Júnior IF. Intra-abdominal fat is related to metabolic syndrome and nonalcoholic fat liver disease in obese youth. BMC Pediatr. 2013 Aug 7;13:115.

25. Weinstock RS, Drews KL, Caprio S, Leibel NI, McKay SV, Zeitler PS; TODAY Study Group. Metabolic syndrome is common and persistent in youth-onset type 2 diabetes: Results fom

6. Yahia N, Brown CA, Snyder E, Cumper S, Langolf A, Trayer C, Green C. Prevalence of Metabolic Syndrome and Its Individual Components Among Midwestern University Students. J Community Health. 2017 Aug;42(4):674-687.

27. Yen SL, Chiu TY, Lin YC, Lee YC, Lee LT, Huang KC. Obesity and hepatitis B infection are associated with increased risk of metabolic syndrome in university freshmen. Int J Obes (Lond). 2008 Mar;32(3):474-80. 